\title{
Intraductal Papillary Adenocarcinoma with Invasion
}

National Cancer Institute

\section{Source}

National Cancer Institute. Intraductal Papillary Adenocarcinoma with Invasion. NCI

Thesaurus. Code C7439.

A breast adenocarcinoma characterized by the presence of an intraductal papillary carcinomatous component and an invasive carcinomatous component. 